\title{
ReSEARChArticle
}

\section{Phenotypic variability in the shape of nuts recorded in the seedling raised walnut (Juglans regia L.) population in the Kashmir valley}

\author{
IMTIYAZ AHMAD LONE
}

\begin{abstract}
SUMMARY
The present investigation entitled phenotypic variability in the nut shape in the seedling raised natural population of walnut (J. regia) in the Kashmir valley was carried out in order to document the available genetic variability in walnut germplasm and to select elite walnut genotypes possessing superior attributes and quality traits. During the survey, data was recorded on one hundred fifty two (152) walnut trees growing in different areas of Kashmir valley. Remarkable variability was observed in seedling walnut trees for different morphological, nut and kernel characters. Similarly, variations were also reported for other characters viz., tree vigour, growth habit, branching habit, leaflet shape, shoot colour, nut shape, shell texture, shell colour, shell seal, shell strength, shell integrity, kernel shrivel and kernel colour. Studies on nut shape revealed nut shape varied from round to cordate. Majority of the genotypes (56) that represented 36.85 per cent population had round nut shape followed by 36 genotypes (23.69\%) that had ovate nut shape; 8 genotypes (5.27\%) had triangular nut shape; 10 genotypes $(6.58 \%)$ had broad ovate nut shape; 7 genotypes $(4.60 \%)$ had short trapezoid nut shape, 3 genotypes (1.97\%) had long trapezoid nut shape, 16 genotypes $(10.52 \%)$ had broad elliptic nut shape and the remaining 13 genotypes $(8.55 \%)$ had elliptic nut shape.
\end{abstract}

Key Words : Walnut, Variability, Nut shape

How to cite this article : Lone, Imtiyaz Ahmad (2017). Phenotypic variability in the shape of nuts recorded in the seedling raised walnut (Juglans regia L.) population in the Kashmir valley. Internat. J. Plant Sci., 12 (2): 302-308, DOI: 10.15740/HAS/ IJPS/12.2/302-308.

Article chronicle : Received : 10.05.2017; Revised : 10.06.2017; Accepted : 25.06.2017

\section{AUTHOR FOR CORRESPONDENCE}

IMTIYAZ AHMAD LONE, Division of Pomology, Sher-e-Kashmir University of Agricultural Sciences and Technology of Kashmir, SHALIMAR (J\&K) INDIA 